\title{
Stress, Coping, Dyadic Coping and Oncological Pathology: An Overview
}

\author{
Floriana Irtelli* \\ Catholic University of the Sacred Hearth, Milan \\ Submission: October 21, 2018; Published: November 09, 2018 \\ *Corresponding author: Floriana Irtelli, Catholic University of the Sacred Hearth, Milan, Italy
}

\begin{abstract}
Patients with cancer face many physical and emotional stressors, and research has shown that distress can impact disease progression and survival. In this article it's analyzed the model of stress and coping to examine the cancer survivors' self-reported efforts to manage stress and their consequences for health. The use of some coping strategies might be helpful to extend survival time and the understanding of these coping strategies it's very important, so negative and positive coping styles are described. During cancer, coping strategies adopted by patients and their partner have an effect on their own emotional state and quality of life, so these findings highlight the importance of further investigating also this topic.
\end{abstract}

Keywords: Stress; Coping; Dyadic Coping; Cancer; Oncology; Quality of Life.

\section{Stress and Stressors}

Hans Seyle the first to use the term stress to describe a series of physical and psychological responses to adverse conditions [1]. Originally the "just being sick" syndrome [2] represented the stereotypical response of an organism to a wide range of physical, biological or chemical stimuli. Later, looking for a specific term that represented this answer, Seyle used the word "stress". Stress is an English term that means "pressure", and it's used to indicate any force that is applied to a body to test its endurance qualities. Over time this term was also used to indicate more specifically a state of aspecific tension of living matter, which manifests itself through tangible morphological transformations in various organs, and particularly in the endocrine glands under the control of the hypophysis [3]. The term stress, which describes a reaction, is distinguished from the stressor (the stressful event, or stressful factor), term that describes the stimulus factors that can cause the aforementioned reaction of the organism. Stressful factors can be serious factors (death of a loved one or a serious illness), minor factors (small facts of daily life), acute factors (accidents), chronic factors (for example a very competitive working environment) [4]. Seyle also distinguished between eustress (or good stress) and distress; they were originally included in the broader definition of stress but were immediately disclosed as separate one from the other. Seyle claimed that stress is an inevitable consequence of living, but the distress appears when the stimuli (both in their psychological and physiological aspects) overwhelm the skills and energies that the person can and believes he can spend in maintaining homeostasis. The stimulus can therefore have a more or less positive meaning $[1,5]$.
This idea was well illustrated by Holmes and Rahe in the construction of the "Social Readjustment Rating Scale" [6]: every stress can be classified in eustress and distress, the first is caused by a question considered disproportionate in size, while the "eustress" is caused by a question considered acceptable, which creates a moderate and not excessive level of tension that allows to successfully deal with the requests. However this is just one aspect of eustress. The concept of an optimal stress level comes from the studies of Yerkes and [7]; they explained how increasing stress is beneficial for performance as long as it is moderate, after which the performance will deteriorate according to an inverted U-diagram [8]. To clarify the association between the theory of Yerkes \& Dodson [7] and that of Seyle it is necessary to explain that the nature of each stimulus depends on how each person interprets it and chooses to react to it. From the individual depends on whether a stress will be eustress or distress. Eustress is the primary result of a positive perception of the stressor, while distress is the result of a negative perception. The classification depends therefore on what the stressor represents for the individual, from what value is attributed to the stressor. Seyle suggested that learning to respond to stressful stimuli with positive emotions (like hope), maximizes eustress and minimizes distress, instead responding with negative emotions (such as despair), greatly increases the distress [5].

In the perception of the stressor, and in the attribution of meaning to it, some characteristics of the individual intervene: presenting an internal locus of control (and self-efficacy) has very different implications that presenting an external locus 
of control. Self-efficacy is the belief of being able to control environmental challenges by providing an adaptive action [9], and in agreement with cognitive social theory [9] the selfperceived behavior strongly influences the person and it's positively associated with adaptation; as a matter of fact it's related to active coping and negatively to passive coping $[10,11]$. Hans Seyle also introduced the notion of "general adaptation syndrome" to describe the way in which the person copes with stressful events; he distinguishes three phases that follow one another in this order:

a. Alarm phase: The autonomic nervous system is activated to face intense stressful events;

b. Resistance phase: There is an adaptation to the stress and, if the stress is too intense, there are transient manifestations such as the enlargement of the adrenal glands, gastrointestinal ulcers, etc.;

c. Exhaustion phase: If the stress factor remains or if the person is not able to give adequate responses, the organism will meet irreversible responses, including death.

\section{Coping and Cancer}

Lazarus has integrated Seyle theory with some cognitive aspects related to the subjective processing made by the person about the specific stressors, creating a more complex model. As a matter of fact the same event, as already anticipated, can have different meanings for different individuals, and in front of stressful factors different people react with different ways and outcomes. An optimal adaptation requires that the reaction strategies are active but also multiple, flexible and calibrated on the stressful events involved. The stress response is therefore modulated in two phases: the first, that of perception and processing of stressful factors and the second phase of coping with these factors. The characteristics that intervene in this second step, and modulate the strategies of reaction, are called coping skills, and the whole process of reaction and coping of stress is indicated by the term coping $[12,13]$. Since the 1960s, awareness has grown that while stress is an unavoidable aspect of the human condition, Coping makes a big difference with regard to the outcome related to adaptation to it [13-16]. Today, referring to the Psycho-Oncological context, for Coping we mean the cognitive and behavioral style of an individual in dealing with the pathology, i.e. the ability to cope with problems and their emotional consequences, and it refers to the adaptation of the individual. This concept is really fundamental in situations of complex illness like cancer.

It is considered to be a sequential series of stressful events among its different meanings: diagnosis, aggressive treatments, fear of death, changes in the social and physical context [17]. In this context the concept of Coping represents a parameter able to exert a considerable influence on the different ways of psychological reaction and psychosocial adaptation to the disease, on the possible psychopathological complications, on the quality of fife following diagnosis, on compliance with antineoplastic treatments, and also on the biological course of the disease [18-20]. The patient's ability to face a possible situation of existential crisis, triggered by the neoplasm, depends on a set of factors. According to Lazarus and Folkman [13] and Holland Rowland [21], the psychological impact of a stressor (in this case cancer) is influenced both by the characteristics of the individual and by the characteristics of the stressor. With regard to the characteristics of the stressor we must therefore take into account the type of pathology (symptomatology, course, therapy, collaterals); regarding the characteristics of the individual, they reveal themselves as complex, multiple and strongly intertwined: the level of adaptation preceding the neoplasm (for example in relation to previous situations of illness); the meaning attributed to the disease [11]; the history of the subject, his personality and cultural and religious factors; the patient's psychological structure (age, introspective capacity, education, possible psychiatric disorders); Coping Style [22]. The type and extent of social support is also important [23]. For prognostic purposes the personal meaning that each patient attributes to the disease is of particular importance [19] and according to Lipowsy there would exist eight different possible meanings attributable to the diagnosis of cancer: illness as a punishment, an enemy to fight, a loss of sexual identity or, a possibility of personal growth, a challenge to one's own mental resources, as a strategy, as a relief for patients who had already reduced their expectations of life [14].

Decisive are the consequences of this attribution of meanings: if the disease is perceived and interpreted as punishment, it is possible to activate models of reaction in which the fault prevails, with consequent behaviors of fatalism and resignation; if the perception that prevails is seeing the cancer as an unwelcome guest or an enemy, the ways that can emerge will be characterized by an acceptance of the challenge, open struggle and willingness not to give up; if there is the perception that the disease will involve the removal from the loved ones, behaviors of dependency and need of continuous reassurance can be activated [20].

In the 1970s Arvey Weisman discussed two concepts: Coping and vulnerability. In his studies he shown that the so-called "Good Copers" have the persistent belief that they will be able to cope with the disease; the "Bad Copers" are characterized by regret and pessimism. The vulnerability is divided into dysphoric type and dispositional type. The former concerns patients reporting current depressive experiences and symptoms, the latter, reflects some character dynamics that leads to alienation, annihilation, and desperation [24-26]. Weisman also proposed in 1979 a model of Coping, considering some existential vulnerabilities associated with the cancer diagnosis.

He identified four phases:

a. Existential situation: It includes the impact of the diagnosis, the confrontation with death and anxieties about the future. 
b. Adaptation and Mitigation: Variable levels of impairment are present, and the focus is on the pragmatic aspects of the treatment and its effects; there is a strong sense of being changed. The characteristic activity of this phase is vigilance.

c. Relapse and Recurrence: Existential concerns are recalled and it may be more difficult to show optimism. The goal of the patient is often to maintain the control on the situation.

d. Deterioration and Decline: This involves a significant deterioration in functional abilities; there is often a tendency to focus on palliative care.

Regarding the specific coping styles, Weisman and Worden identified in 1984, fifteen different Coping Styles towards the neoplasia, corresponding to as many defensive mechanisms:

a. Rationalization: To search for information about the disease;

b. Repression: To avoid dwelling on the problem;

c. Displacement: To focus your interest on other activities to distract yourself;

d. Redefining: To grasp the positive aspects of the diagnosis;

e. Fatalistic Resignation: To show a passive attitude towards the diagnosis;

f. Projection: To attribute to someone the cause of the disease;

g. Internalization: To develop self-accusatory attitude towards the disease;

h. Minimization: To underestimate the diagnosis;

i. Compliance: To use of the support and indications of trusted people;

j. Sharing of concerns: To develop the tendency to express and share one's own experiences;

k. Rational reflection: To evaluate possible therapeutic alternatives;

l. Reduction of stimuli: To develop the tendency to introversion and social isolation;

m. Tension reduction: To reduce psychological tension (for example abusing of substance);

n. Comparison: To confront the problem;

o. Acting -out: To react impulsively.

There is a wide range of reactions to the cancer diagnosis [19] and after Weisman and Worden, other scientists attempted to describe the most frequent ways in which people manage their disease situation [17]. The coping styles were then classified by
Greer \& Watson [27]: they approached the Appraisal process and Coping's response in a single construct called "Mental Adjustment", which can be used to define the Coping styles. They are: Combative Spirit: characterized by an optimistic confidence in the ability to fight and defeat the disease; Avoidance: characterized by a tendency to minimize the pathological event and by an indifferent attitude, with a low propensity to seek further information on the type of pathology; Fatalistic Attitude: the tendency to develop passive resignation towards illness, stoicism and absence of opposition; Anxious worry: characterized by a reaction of alarmism and anxiety, anxious manifestations and profound repercussions on the patient's quality of life; Despair: feeling of uselessness, ideas of death, depressive experiences and poor therapeutic compliance [27].

Coping Styles were hierarchically classified by Greer, according to their influence on the survival of cancer patients: on the basis of the results obtained, in the first position the Author posed the Combativeness style, in second the Avoidance; in the third Fatalism. Desperation and Anxious Concern were revealed to be the worst [27-29]. I will describe them on the basis of this hierarchy, integrating some findings related to this theme:

\section{Combativity}

This style is characterized by the patient's acceptance of the challenge of defeating the disease, to resume the words of the creators of this dimension, Greer and Moorey : the patient sees the diagnosis as a challenge, has an optimistic vision of the future, believes that it is possible to exercise control over the disease, and manifests responses to confrontation aimed at direct confrontation; who adopts this strategy therefore has an internal locus of control and wants to know as much as possible of the pathology, asks to intervene in the choice of therapies, adheres to the proposed treatments, participates in the proposed complementary interventions and makes changes to their lifestyle in order to preserve health, for example by changing diet [20,30]; this strategy can be defined as Active, Positive Coping, as it represents a tendency to confront and actively cope with the disease $[30,31]$. It can be associated both in the short and long term with the Adaptation Denial, which protects from anxiety and depression and is expressed in the tendency to minimize the gravity of the situation and in the lively hope of success in the battle against cancer [31,32].

The optimism that characterizes this Coping style has beneficial effects on health, well-being and the quality of life of those who adopt it [33]. It is important to underline that recent research carried out on patients affected by cancer reveals that the Coping style itself mediates the positive effect of optimism on quality of life and emotional, cognitive and social functioning. Combativity is correlated to lower levels of anxiety and demoralization [20]. Patients who face the unfortunate event with a combative spirit use answers summarized with these statements: "I see this disease as a challenge", "I am determined to defeat the tumor", "I am very optimistic"; they adopt more 
flexible and differentiated cognitive and behavioral strategies; this attitude can be represented by the statement: "I am actively trying to improve my health". This Coping style is associated with lower psychological morbidity, a feeling of greater personal control over the health state, and a more favorable course of the disease, thus a greater survival [28,34-39]. This strategy of Coping and Despair proved to be the most stable dimensions, as associated with personality traits, in accordance with the 1997 Folkman Theory; they are therefore considered hardly subject to variation [40] and they are negatively correlated with each other [41].

\section{Avoidance}

This strategy is very complex, it was neither related to optimism/pessimism [40], nor generically to dimensions related to "Adaptation" [41,42], it is characterized generically by the tendency to avoid facing directly all the issues related to the disease [20], the use of euphemisms to talk about this topic [43], and it is connected to the use of the defense mechanism "denial" (to avoid seeing unpleasant aspects of reality); it's a very common strategy and often plays a very useful action in protecting from anxiety, but it can cause problems if it is used as a single form of psychic defense, therefore it has been distinguished in healthy denial and negative denial [30]; the first form can be defined as a natural method of emotional self-protection [30], which has positive effects on health [28,29], for this reason it has been called "Healty", Druss (1988) [30]. In this case we will expect to find a Combat Coping style accompanied by this Coping Style. The second form of denial instead contemplates more extreme and exclusive forms: it can lead to diagnostic delays, poor collaboration with medical therapies; the abuse of this mode of coping is linked to the risk of stopping important communications with relatives, and it can be combined with anxiety or depression [30]. A high level of avoidance, used as the only strategy of confrontation , can also lead to an unrealistic self-efficacy perception [41] and alexithymia [31].

\section{Fatalism}

This is a strategy characterized by a fatalistic attitude to resignation and passive acceptance of the disease [31,43], the conviction to have little control over events, resigned acceptance of what fate has established: those who adopt this approach recognize the gravity of the situation, but accept it as their destiny $[30,20]$. We must therefore point out that the tendency to perceive external events as related to the destiny, is typical of those who have an external locus of control: this causes a poor adaptation to the disease and a lack of responsibility for one's health situation [30,20]. Greer in 1990 had attested as the use of fatalism, the anxiety and the despair were related to a lower survival 15 years after diagnosis, this was also confirmed by other researches [41]; another research has shown that it correlates with higher levels of distress after one year from surgery [44]; It has also been shown how fatalism is particularly related to despair [41], and it has negative psychological effects throughout the course of the disease: it negatively correlates with both optimism at the time of diagnosis, negatively mediating its effect on Global Heath Quality of Life (GHQOL) [40]. The resignation that fatalism involves is positively correlated with high levels of anxiety and depression [43], and they have also been positively correlated with feelings of despair, characteristic of the "Coping Style" Despair. Fatalism has been shown to be associated with less survival not only in the oncological context, but also in other contexts, such as heart disease [45].

\section{Anxious worry:}

This strategy is characterized by constant concern for the disease and feelings of danger [43], a high level of anxiety and depression [46] and placing the disease in a central position with respect to one's own existence [20]. It was negatively correlated with social and emotional functioning [40]. Those who adopt this coping style are constantly seeking reassurance, request for visits or, on the contrary, escape from the care context [20]. It was highlighted how this mode of coping negatively affects patients' survival, even after ten years from the diagnosis [47]. Recent studies have shown that this strategy fortunately decreases after the first months of diagnosis [32,42,48]. Finally, it was correlated with desperation and fatalism [41].

\section{Despair}

This coping style is characterized by feelings of defeat, the sensation of being overwhelmed by the diagnosis, and a pessimistic attitude towards the disease [31,43]; it is related to high levels of Anxiety and Depression, poor cognitive strategies and the belief that to have little control over events. This style is also correlated to poor therapeutic adherence: the occurrence of the disease is expected as an event that leaves no way out [20]; as a matter of fact there is a correspondence between despair and demoralization, and there are: affective symptoms of existential distress, loss of meaning and goals of life, the cognitive propensity to pessimism, a sense of personal failure, lack of motivation to face the negative event, a sense of social isolation and alienation [46]. This is a Coping style associated with pessimism, a dispositional trait, and it's generally not subject to changes over time, such as Combativity. Despair is related to a lower quality of life and to worse social and cognitive functioning [40].

The emotional reactions and psychic defenses are fundamental areas for understanding the meaning attributed to the disease [20]. We need to specify that coping styles are early modulators of the adaptation responses to the disease, and their early knowledge can predict the person's response to the illness [49]; "low risk" patients have an active, flexible and differentiated coping style, characterized by redefinition of problems and compliance with therapy [20]. In general, strategies characterized by a more efficient and diversified way of dealing with problems, compared to more passive styles, characterized by feelings of desperation and impotence, are more effective for a better adaptation $[19,20]$. Those who face 
the unfortunate event with combativeness use responses that can be summarized with the statement "I see this disease as a challenge", adopt more flexible and differentiated cognitive and behavioral strategies ("I am actively trying to improve my health") that favor a more positive view of the negative event, leading to grasp a deeper meaning of the existence. This this style is associated with a lower psychological morbidity, a feeling of greater personal control on the state of one's health, a higher quality of life and a more favorable course of the disease [34-36,43,50,51]. Understanding the type of coping style has a particular importance because if it is functional and effective the adaptation to the disease can also turn into a personal growth. On the contrary, if the situation is interpreted as too stressful, the onset of psychopathological reactions and a state of intense subjective suffering is possible [20]. Personality variables (such as dominance and interpersonal trust) and the associated processes of appraisal and coping, have a significant correlation with psychological symptoms and adaptation [15]. Among the psychological characteristics that can influence the coping style there are aspects related to individual history and personality characteristics. As already mentioned, the tendency to perceive external events as inevitably linked to fate (external locus of control) tends to favor maladaptive approaches to the disease, while the tendency to perceive events as manageable (internal locus of control) facilitates more adaptive ways of coping. Moreover, people with personality disorders or with inflexible psychological defenses, are patients at risk of psychopathological complications. The previous level of patient adaptation is significantly associated with the coping style [20]. The knowledge of the individual coping style is also important in the oncological clinical practice: there are different relational implications and different ways of relating that should be taken in consideration by the professional figure because there are different kind of patients (for example the subjects that want to have detailed information in order to deal with these, and the patients that want to leave to other persons the management of their problems) [52].

\section{Dyadic coping}

Starting from the evidence that patients with cancer and their loved ones (particularly the companion) are hit jointly by the stress of this disease [53-55], several researches about coping have investigated how partners can cope together with stress, and how each of the dyad attempts to cope mutually influence each other [56,57-63]. An evolution in the research about coping in the focus on concept of dyadic coping [64], that is the way to deal together with the disease; it considers the experience of stress at the dyadic level of the couple and the process of mutual influence, in which the stress of one partner can influences the other [65]. This concept emphasizes that there is an interdependence between the coping and social support: the success of the coping is strongly linked to the response of the other significant ones [64]. Bodenmann studied dyadic stress and created a dynamic theory of the dyadic coping process. He defined dyadic stress as a distinct form of social stress, which includes common concerns and emotional intimacy between two persons. Specifically, it is relevant that a stressful event always affects both partners, directly and indirectly. The concept of dyadic coping is part of an interpersonal process that involves both partners [66-69] and it's based on the transactional stress theory of Lazarus and Folkman [13] but expands it with some systemic and process-oriented dimensions. Starting from the question: "How does stress affect marriage? How does dyadic coping can influence the relationship between stress and the quality of married life?"

He has distinguished between positive and negative forms of dyadic coping. Among the positive forms there are:

a. Supportive Dyadic Coping: It is present when one partner supports the other in his attempts to cope. This can be expressed through acts such as assisting others in the daily tasks, empathic listening, practical help, solidarity. It's not only altruistic behavior but also has as its secondary purpose the reduction of partner stress [67].

b. Common Dyadic Coping: Both partners participate in the coping process more or less symmetrically or in a complementary way, implementing problem solving, realizing a common search for information, sharing feelings or relaxing together.

c. Delegate Dyadic Coping: It manifests itself when one of the two partners is asked to take on more responsibility for trying to reduce the tension of the other, so the partner involved accepts and carries out more tasks.

Among the negative forms of dyadic coping we can find:

a. Hostile dyadic coping: In this case the support provided is accompanied by sarcasm, minimization of the discomfort of the other and interpersonal distance.

b. Ambivalent dyadic coping: It is applied when a partner provides unwilling support or a support with the belief that the care will be useless.

c. Superficial dyadic coping: It consists of a not sincere support, and it is expressed, for example, trying to support the partner without empathy.

Acitelli and Badr [70] have dedicated themselves more specifically to dyadic coping in the context of chronic illness, such as cancer. The authors have investigated (both in the role of healthy partner and sick partner) the difference in the behavior of men and women, and different expectations (depending on the gender) towards the partner. The data obtained from their studies show that the chronic disease should not be interpreted as an individual challenge but a relational challenge; it emerged in fact that if the partners talk about their relationship and keep a good communication, their health will hardly affect their marital satisfaction, especially for women: specifically, the more husbands are involved in a dialogue with the sick wives more 
there will be satisfaction for their relationship with their wives. Women, with their interdependent approach to relationships, are more likely to pay attention to these elements and derive good consequences for their relationship satisfaction.

On the contrary, it has been noted that if the ill partner has great emotional needs and the healthy partner acts in accordance with the traditional gender role, sick women suffer more than men in the same condition. Female subjects, on the other hand, in the role of the healthy partner tend more to give emotional support through dialogue, and it has been verified that the more husbands talk about their relationship, the more this generates support and favors a positive outcome. Acitelli and Badr [70] have also highlighted how perceiving the disease as "our disease", rather than "my illness", has significant implications for coping and perceived social support: it's better for the couple wellbeing to understand the tumor as a theme of the relationship, rather than a purely individual matter; this leads to behave like a team that tackles the routines of the disease together, solves the problems together, thus reporting a better adaptation [70].

\section{Conclusion}

Revenson et al. [65] have described how keeping high the quality of the marital relationship, is an intact part of the coping process (placing it before the individual needs). Fundamental to this purpose is the ability to communicate and the ability to always be empathetic. The authors have also highlighted the mutual influence between the coping styles and the importance of their compatibility; as a matter of fact they proposed congruence as a conceptual framework to analyze the interlocking of coping strategies. Depending on different connotations between the coping modalities, the clustered Coping Copies have been grouped together like this: effortful partnership (presence of a fairly high level of congruence between coping and the tendency to use problem-focused strategies); problem solvers with focused coping on emotions (moderate level of congruence, use of problem solving tactics, and strategies focused on emotion); minimalist copers (high congruence in not having a predominant strategy); patient facing alone (coping styles not congruent). The analysis carried out on the basis of these clusters revealed that it was not so problematic to present dissimilar styles of coping but to fully understand this aspect it was necessary also to take into consideration the couple's life context and the perception of it [65].

Karen Kayser has instead proposed the "Stress- Coping Cascade"[71], a phenomenon triggered after the diagnosis of the disease: when a Coping strategy used to cope with an acute form of stress is no longer functional, the patient tends to extend his research of support more and more externally to its natural nucleus, until it finds an answer that satisfies its needs [72]. The Coping process follows a dynamic temporal order; in most cases, both partners initially try to deal with the stressful situation with individual strategies. When individual coping attempts are no longer effective, then the dyadic coping is put in the foreground; if it does not prove to be sufficient, then other social support is required (first of relatives and friends, then of colleagues). Finally, even if the social coping does not bring results, professional help could be required [71]. This can happen not only because of the incapacity or unwillingness of family members, but because of a possible integration of different forms of support [72]. Kayser examines coping type by a relational perspective, emphasizing how patients do not face alone the stressors, but in the context of their interpersonal relationships [71,73] more frequently than the relationship with their partner [74-77]. The author then highlights how cancer is a "We-disease: a disease that involves a plural dimension more than the individual dimension [78]. Specifically, the stressors with which patients affected by cancer and their partner must jointly confront are: medical stressors associated with negotiating a complex organization of care, making decisions about treatments and absorbing a lot of information; instrumental stressors due to the need to manage medical needs and at the same time the tasks of daily routine; social stressors that manifest themselves in having to reveal the diagnosis to relatives and friends; emotional stressors like depression, anxiety, sadness; existential stressors experienced by the couple regarding the meaning of life, the injustice of destiny, the possibility of death [71].

Karen Kayser stated how numerous researches have shown that partner support $[61,73-75,79,80,81]$ and a functional dyadic coping [82-84] can reduce the stress caused by the disease; as a matter of fact she is a contributor to the Partners in Coping Program (PICP) (2005): an innovative treatment with focus on couples who are coping with a recent diagnosis of cancer. The PCIP is based on improving the skills that favor the functioning of the dyads. It refers to the Bodenmann theory of dyadic stress [85-88] and starting from the consideration of the stressors mentioned above, it is proposed to focus on the characteristics of the relationship, the support between partners and the dyadic coping: this obviously has an important influence on the adaptation to the disease. These findings suggest that both patients and partners should be included in psychosocial programs, which develop and reinforce their ability to cope with cancer; the quality of the dyadic relationship may be critical in determining both partner and survivor distress and needs and may prove a useful target for psychosocial interventions $[71,89,90]$.

\section{References}

1. Selye H., (1964) From Dream to Discovery McGraw Hill New York, USA.

2. Selye H (1936) A Syndrome Produced by Different Nocuous Agents. Nature 138: 32.

3. Selye H (1993) History of the Stress Concept. Handbook of Stress: Theoretical and Clinical Aspects.

4. Sanavio E, Cornoldi C (2001) Psicologia Clinica Il Mulino, Ezio Sanavio,Cesare Cornoldi Bologna: 208.

5. Seyle H (1987) Stress Without Distress. Transword, London, UK.

6. Holmes TH, Rahe RH (1967) The Social Readjustment Rating Scale. Journal of Psychosomatics Research 11: 213-218. 
7. Yerkes RM, Dodson JD (1908) The Relation of Strength of Stimulus to Rapidity of Habitformation. Journal of Comparative Neurology and Psychology 18: 459-482.

8. Benson H, Allen RL (1980) How Much Stress is Too Much. Harvard Business Review 58(5): 86-92.

9. Bandura A (1997) Self-efficacy: The Exercise of Control. Freeman: New York, USA.

10. Luszczynska A, Scholz U, Swarzer R (2005) The General Self-Efficacy Scale: Multicultural Validation Studies J Psychol 139(5): 439-457.

11. Rottmann N, Dalton SO, Christensen J, Frederiksen K, Johansen C (2010) Self Efficacy, Adjustment

Style and Well-Being in Breast Cancer Patients: a Longitudinal Study Quality of Life Research, 19(6): 827-836.

12. Lazarus RS (1966) Psychological Stress and The Coping Process. Mc Graw-Hill: New York, USA.

13. Lazarus RS, Folkman S (1984) Stress Appraisal and Coping. Springer: New York, USA.

14. Lipowsky ZJ (1970) Physical Illness, the Individual and the Coping Processes Psychiatry Me 1(2): 91-102.

15. Folkman S, Lazarus RS, GruenR J, De Longis A (1986) Appraisal, Coping, Health Status and Psychological Symptoms. J Pers Soc Psychol 50(3): 571-579.

16. Lazarus RS (1993) Coping Theory and Research: Past, Present and Future. Psychosomatic Medicine, American Psychosomatic Society.

17. Grassi L, Costantini A (2003) Terapia di Gruppo per Pazienti Oncologici: Manuale di Intervento Psicosociale per Basato sulle Evidenze. MacGraw-Hill, United States.

18. Biondi M, Costantini A, Grassi L (1995) La Mente e il Cancro. Roma: Il Pensiero Scientifico Editore.

19. Torta R, Mussa A (1997) Psic Oncologia: Basi Biologiche, Aspetti Clinici e Approcci Terapeutici. Centro Scientifico Editore.

20. Grassi L, Biondi, Costantini A (2003) Manuale pratico di PsicoOncologia. Il pensiero scientifico editore, Roma, Italy.

21. Holland JC, Rowland JH (1989) Handbook of Psycho-oncology: Psychological Care of the Patient with Cancer. Oxford University Press, New York, USA.

22. Lesko LM, Holland JC (1988) Psychological Issues in Patients with Hermatological Malignancy Recent Results in Cancer Research 108: 242-270.

23. Kwan ML, Ergas IJ, Somkin CP, Quenesberry CP, Neugut AI (2010) Quality of Life Among Women Recently Diagnosed with Invesive Breast Cancer: the Pathaways Study. Breast Cancer Res Treat 123: 507-524.

24. Weisman AD, Worden JW (1977) Coping and Vulnerability: a Research Report. Massachusetts General Hospital, Boston, USA.

25. Weisman AD (1979) Coping With Cancer. Mc Graw-Hill, New York.

26. Weisman AD (1989) Vulnerability and the Psychological Disturbances of Cancer Patients. Psychosomatics 30(1): 80-85.

27. Greer S, Watson M (1987) Mental Adjustment to Cancer: Its measurement and prognostic importance. Cancer Surv 6: 439-453.

28. Greer S, Morris T, Pettingale KW (1979) Psychological response to breast cancer: Effect on outcome. Lancet 2: 785-787.

29. Greer S, Morris T, Pettingale K, Haybittle J (1990) Psychological Response to Breast Cancer and 15-year Outcome. Lancet 335(8680): 49-50.

30. Barraclough J (2001) Cancro ed Emozioni: aspetti emozionali e psicologici nel paziente oncologico. Centro Scientifico Editore.

31. Grassi L, Buda P, Cavana L, Annunziata M, Torta R, et al. (2005) Styles of Coping with Cancer: The Italian version of the MINI-Mental Adjustment to Cancer (MINI-MAC) Scale. Psychooncology 14(2): 115-124.

32. Nosarti C, Jonathan V, Roberts, Crayford T, McKenzie K, Anthony SD (2002) Early Psychological Adjustment in Breast Cancer Patients, A Prospective Study Journal of Psychosomatic Research 53(6): 11231130.

33. Allison PJ, Guichard C, Gilain L (2000) A Perspective Investigation of Dispositional Optimism as Predictor of Health-Related Quality of Life in Head and Neck Cancer Patients. Qual Life Res 9(8): 951-960.

34. Burgess C, Morris T, Pettingale KW (1988) Psychological Response to Cancer Diagnosis II. Evidence for Coping Styles. J Psychosom Res 32: 263-277.

35. Pettingale K (1984) Coping and Cancer Prognosis. Journal of Psychosomatic Research 28(5): 363-364.

36. Pettingale KW, Morris T, Greer S, Haybittle JL (1985) Mental attitudes to cancer: an additional prognostic factor Lancet 30(1): 750.

37. Morris T, Pettingale K, Haybittle J (1992) Psychological Response to Cancer Diagnosis and Desease Outcome in Patient with Breast Cancer and Lymphoma Psycho-Oncology 1(2): 105-114.

38. Reynolds P, Hurley S, Torres M, Jackson J, Boyd P, et al. (2000) Use of Coping Strategies and Breast Cancer Survival: Results from the Black/ With Cancer Survival Study American Journal Epidemiol 152(10): 940949.

39. Tschuschke V, Hertensein B, Arnold R, Bunjes D, Denzinger R, et al. (2001) Associations Between Coping and Survival Time of Adult Leukemia Patients Receiving Allogenic Bone Marrow Transplantation. Results of a Prospective Study. J Psychosom Res 50(5): 277-285.

40. Schou I, Ekberg O, Ruland CM (2005) The Mediating Role of Appraisal and Coping in the Relationship between Optimism-Pessimism and Quality of Life. Psychooncology 14: 718-727.

41. Cicero V, Lo Coco G, Gullo S, Lo Verso G (2009) The role of Attachment Dimensions and Perceived Social Support in Predicting Adjustment to Cancer. Psychooncology 18(10): 1045-1052.

42. Hunter MJ, Davis PJ, Tunstall JR (2006) The Influence of Attachment and Emotional Support in Endstage Cancer. Psychooncology 15(5): 431-444.

43. Costa Requena G, Gil F (2009) The Mental Adjustment to Cancer scale: a psychometric analysis in Spanish cancer patients. Psychooncology 18(9): 984-991.

44. Millar K, Purushoyham AD, McLatchie E, George WD, Murray G (2005) A 1-year Prospective Study of Individual Variation in Distress, and Illness Perceptions, After Treatment for Breast Cancer J Psychosom Res 58(4): 335-342.

45. Lewis SC, Dennis MD, Rourke OSJ, Shape M (2001) Negative Attitudes Among Short-Term Stroke Survivors Predict Worse Long-Term Survival Stroke 32: 1640-1645.

46. Grassi L, Rossi E, Sabato S, Cruciani G, Zambelli M (2004) Diagnostic Criteria for Psychosomatic Research and Psychological Variables in Breast Cancer Patients. Psychosomatics 45(6): 483-491.

47. Watson M, Janis Homewood, Jo Haviland, Judith M Bliss (2005) Influence of psychological response on breast cancer survival: 10-year follow-up of a population-based cohort. European Journal of Cancer 41(12): 1710-1714.

48. Grandi S, Fava GA, Cunsolo A, Saviotti FM, Ranieri M, et al. (1990) Rating Depression and Anxiety After Mastectomy: Observer Versus Self-Rating Scales. Int J Psychiatry Med 20: 163-171. 


\section{Global Journal of Intellectual \& Developmental Disabilities}

49. Stanton AL, Danoff-Burg S, Huggins E (2002) The First Year After Breast Cancer Diagnosis: hope and coping strategies as predictors of adjustment. Psychooncology 11(2): 93-102.

50. Gilbar 0, Or Han K, Plivazky N (2005) Mental Adjustment, Coping Strategies, and Psychological Distress among End-stage Renal Disease Patients. J Psychosom Res 58(6): 471-476.

51. Henoch I, Bergman B, Gustafsson M, Gaston Johansson F, Danielson E (2007) The Impact of Symptoms, Coping Capacity, and Social Support on Quality of Life Experience Over Time in Patients with Lung Cancer. J Pain Symptom Manage 34(4): 370-379.

52. Miller SM (1995) Monitoring versus Blunting Styles of Coping with Cancer Influence: the information patients what and need about their disease. Implication for cancer screening and management. Cancer 76(2): 167-177

53. Northhouse LL (1987) Adjustment of Patients and Husbands to the Initial Impact of Breast Cancer Nurs Res 36(4): 221-225.

54. Northouse LL (1990) A Longitudinal Study of the Adjustment of Patients and Husbands to Breast Cancer. Oncol Nurs Forum, 16(4): 3945.

55. Northouse LL, Cracchiolo CA, Appel CP (1991) Psychological Consequences of Breast Cancer on Partner and Family. Semin Oncol Nurs 7(3): 216-223.

56. Baider L, Koch U, Eascson R, Kaplan De Nour A (1998) Perspective Study of Cancer Patients and Their Spouses: The Weakness of Marital Strength" Psycho-Oncology 7: 49-56.

57. Baider L, Cooper CL, De Nour AK (2000) Cancer and the Family, (2 $2^{\text {nd }}$ edn) Wiley: New York, USA

58. Bradr H, Carmack CL, Kashy DA, Cristofanilli M, Reverson T (2010) Dyadic Coping in Metastatic Breast Cancer. Health Psychol 29(2): 169180

59. Hagedoorn M, Buunk BP, Kuijer RG, Wobbes T, Sanderman R (2000) Couples Dealing with Cancer: role and gender differences regarding psychological distress and quality of life. Psychooncology 9: 232-242.

60. Manne SL, Grassman M (2000) Perceived Control, Coping Efficacy, and Avoidance Coping as Mediators Between Spouses Unsupportive Behaviors and Cancer Patients' Psychological Distress" Send to Health Psychol 19(2): 155-164.

61. Northouse LL, Templin T, Mood D, Oberst M (1995) Couples Adjustment to Breast Cancer and Being Breast Disease Psychooncology 7(1): 3748.

62. Pat-Horenczyk R, Machyevsky D, Brom D, Swartz I, et al. (2009) Dyadic Coping Among Breast Cancer Patients Treated With Radiotherapy" Journal of Clinical Oncology 27: 15s.

63. Zunkel G (2002) Relational Coping Processes: Couple's Response to a Diagnosis of Early Stage Breast Cancer. Journal of Psycho Oncology 20 39-55.

64. Revenson TA, Kayser K, Bodenmann G (2005) Couple Coping with Stress. Emerging Perspectives on Dyadic Coping", American Psychological Association, Washington, USA.

65. Revenson TA, Abraido LAF, Majerovitz SD, Jordan C (2005) Couples Coping with Chronic Illness: What's Gender Got to Do with It? In: Revenson TA, et al. (Eds.) Couple Coping with Stress. Emerging Perspectives on Dyadic Coping. American Psychological Association, Washington, USA, pp. 137-156

66. Bodenmann G (1990) Argerregulation und Deren Bedeutung Fur Die Dyadische Interaktion (Anger Regulation and Its Significance for Diadic Interaction) University of Fribuorg: Fribourg, Switzerland.

67. Bodenmann G (1995) A Systemic-transactional Conceptualization of
Stress and Coping in Couples. Swiss Journal of Psychology 54: 34-49.

68. Bodenmann G (1997) Dyadic Coping- A Systemic Transactional View of Stress and Coping Among Couples: Theory and Empirical Findings. European Review of Applied Psychology 47: 137-140.

69. Bodenmann G (2000) Stress and Coping in Couples. Gottingen, Hogrefe: Germany.

70. Acitelli LK, Badr HJ (2005) My Illness or Our Illness? Attending to the Relationship When One Partner is Ill. In Revenson TA, Kayser K, Bodenmann G (edn) Couples Coping With Stress: Emerging Perspectives on Dyadic Coping. American Psychological Association: Washington DC, USA: 121-136.

71. Kayser K (2005) Enhancing Dyadic Coping During a Time of Crisis: A theory-based Intervention with Breast Cancer Patients and Their Partner. In Reverson TA, Kayser K, Bodenmann G(edn) 136 Couple Coping with Stress. Emerging Perspectives on Dyadic Coping. American Psychological Association, Washington, USA.

72. Saita E (2009) Psico-Oncologia: Una Prospettiva Relazionale Edizioni Unicopli, Milano:278.

73. Kayser K, Sormanti M, Strainchamps E (1999) Women Coping with Cancer: The Influence of

Relationship Factors on Psychosocial Adjustment. Psychology of Women Quarterly 23: 725-739.

74. Kayser K., Sormanti M., (2002) "A Follow-Up Study of Women with Cancer: Their Psychosocial Well Being and Close Relationships" Social Work in Health Care, 35: 391-406.

75. Northouse LL, Templin T, Mood D (2001) Couple's Adjustment to Breast Disease During the First Year Following Diagnosis" Journal of Behavioral Medicine 24(2): 115-136.

76. Zunkel G (2002) Relational Coping Processes: Couple's Response to a Diagnosis of Early Stage Breast Cancer. Journal of Psycho Oncology 20: 39-55.

77. Weis J (2003) Support Groups for Cancer Patients. Support Care Cancer 11(12): 763-768

78. Kayser K, Watson L, Andrade M (2007) Cancer as a We-disease: Examining The Process of Coping from a Relational Perspective. Families, Systems \& Health 25(4): 404-418.

79. Lichtman RR, Taylor SE, Wood JV (1987) Social Support and Marital Adjustment After Breast Cancer Journal of Psychosocial Oncology 5(3): 47-74

80. Primomo J, Yates BC, Woods NF (1990) Social Support for Women During Chronic Illness: The Relationship Among Sources and Types of Adjustment. Res Nurs Health 13(3):153-161.

81. Pistrang N, Barker C (1995) The Partner Relationship in Psychologial Response to Breast Cancer Soc Sci Med 40(6): 789-797.

82. Hannum JW, Giese Davis J, Harding K, Hatfield AK (1991) The Effects of Individual and Marital Variables on Coping with Cancer. Journal of Psychosocial Oncology 9(2): 1-20.

83. Ptacek JT, Ptacek JJ, Dodge KL (1994) Coping with Breast Cancer from the Perspective of Husbands and Wives Journal of Psychosocial Oncology, 12(3): 47-72.

84. Skerrett K (1998) Couple Adjustment to Experience of Breast Cancer Families, Systems \& Health 16: 281-298.

85. Bodenmann G (1990) Argerregulation und Deren Bedeutung Fur Die Dyadische Interaktion (Anger Regulation and Its Significance for Diadic Interaction) University of Fribuorg: Fribourg, Switzerland.

86. Bodenmann G (1995) A Systemic-transactional Conceptualization of Stress and Coping in Couples. Swiss Journal of Psychology 54: 34-49. 
87. Bodenmann G (1997) Dyadic Coping- A Systemic Transactional View of Stress and Coping Among Couples: Theory and Empirical Findings. European Review of Applied Psychology 47: 137-140.

88. Bodenmann G (2000) Stress and Coping in Couples. Gottingen, Hogrefe: Germany.

89. Lafaye A, Petit S, Richaud P, Houede N, Baguet F, Cousson Gelie F (2014)
Dyadic effects of coping strategies on emotional state and quality of life in prostate cancer patients and their spouses. Psychooncology 23(7): 797-803.

90. KuIjer RJ, Ybema JF, Buunk JF, De Jonk, et al., (2000) Active Engagement, Protective Buffering, and Overprotection: The Ways of Giving Support by Intimate Partners of Patients with Cancer. Journal of Social and Clinical Psychology 19: 256-275.

\section{Your next submission with Juniper Publishers} will reach you the below assets

- Quality Editorial service

- Swift Peer Review

- Reprints availability

- E-prints Service

- Manuscript Podcast for convenient understanding

- Global attainment for your research

- Manuscript accessibility in different formats ( Pdf, E-pub, Full Text, Audio)

- Unceasing customer service

Track the below URL for one-step submission https://juniperpublishers.com/online-submission.php 